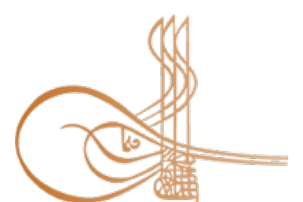

www.turkishstudies.net/social
Turkish Studies - Social Sciences

eISSN: 2667-5617

Research Article / Araştırma Makalesi

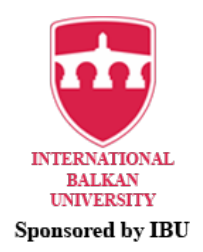

Sponsored by IBU

\title{
Sporda Sponsorluk Üzerine Bir Derleme
}

\author{
A Compilation on Sports Sponsorship
}

\author{
Tuncay Öktem ${ }^{*}$
}

\begin{abstract}
Absract: Sponsorship can be defined as providing cash or in-kind support to an activity to achieve commercial goals. Sponsorship is a tool used in marketing communication aiming positive publicty for companies and brands, by creating awareness with supporting an event (Meenaghan,1983; Bennett,1999). In recent years, the field of sports has found itself a wide area in the application areas of the sponsorship and has brought itself to the fore. The purpose of this study is to analyse the historical development of sponsorship and the concept, types and categories of sponsorship in sports which include the most important source of income for sports teams, individual athletes and sports organizations. In this study, collection and analysis method was used as qualitative analysis to acquire data. In order to collect data, scanning books, articles, thesis, websites and similar resources was performed as scanning method. In this study, it is tried to give information about sponsorship in general and sponsorship in sport in particular. In this context, a research on sponsorship and sponsorship in sports was carried out within the scope of the study. As a result of the researches, it can be said that sponsorship in sports has become one of the most effective communication tools used by institutions in almost every part of the world. As it can be understood from here, it is thought that sports sponsorship will continue its existence and development and increase its share in sponsorship as an indispensable tool of institutions, as a source of income that athletes, organizations, broadcasters and sports clubs will not want to lose.
\end{abstract}

Structured Abstract: In today's market environments, organizations use different methods to communicate with their target groups, to find a place for them and to achieve their corporate goals. Sponsorship, one of these different methods and tools of marketing communication, is a relatively new tool for marketing communication, although it is one of the methods often used by institutions and has been in existence for a long time. In today's intense competitive environment, organizations often use this method to increase their recognition.

In recent years, sponsorship has found itself a wide range of applications. Among these application areas, "sports" is the area that puts itself at the forefront. In this context, the concept of sponsorship in sports was examined in depth, with its various dimensions and categories.

In this study, collection and analysis method was used as qualitative analysis to acquire data. In order to collect data, scanning books, articles, thesis and similar resources was performed as scanning method. In this study, it is tried to give information about sponsorship in general and sponsorship in sport in particular.

With the changes in competition and communication conditions in today's society and today's organizations, many elements in the communication mix have faced new problems (Glogger, 1996; Okay, 2012).

\footnotetext{
* Dr. Öğr. Üyesi, Bayburt Üniversitesi, Beden Eğitimi ve Spor Yüksekokulu, Spor Yöneticiliği Asst. Prof. Dr., Bayburt University, School of Physical Education and Sports, Sports Management ORCID 0000-0003-2770-1774 tuncayktm@gmail.com

Cite as/ Atıf: Öktem, T. (2020). Makale başlı̆̆1. Turkish Studies - Social, 15(4), 2055-2070. https://dx.doi.org/10.29228/TurkishStudies.42812

Received/Geliş: 09 April/Nisan 2020

Accepted/Kabul: 20 June/Haziran 2020

Copyright $($ INTAC LTD, Turkey

Checked by plagiarism software

Published/Yaym: 25 June/Haziran 2020

CC BY-NC 4.0
} 
The fact that organizations experience great competition around the world, as well as the increase of brands, temporary consumer requests, and the increase of multimedia tools (TV channels, social media, mobile phones etc.) can be said as the problems faced by organizations (Radicchi, 2014).

At the same time, the importance of communication for organizations has increased gradually within the framework of this development, and organizations have started to benefit from different communication methods and tools that can reach their target audiences. One of these communication tools and methods is sponsorship (Okay, 2012). Sponsorship can be defined as providing cash or in-kind support to an activity in order to achieve commercial purposes.

In recent years, it has been observed that the interest in sponsorship and the participation of the business world in the sports industry have increased (Morgan et al, 2014). Accordingly, it can be said that sponsorship agreements have become the fastest developing corporate marketing tool (Cunningham et al, 2009). It is also known that $70 \%$ of the sponsorship expenditures of commercial organizations are made to sports organizations (Jensen and Cobbs, 2014).

The sports area has become the most common area where the sponsorship tool is used and started to take the lion's share of the sponsorship investment (Collet and Fenton, 2011). In this context, companies have started working with sports clubs to establish relationships with brands that represent certain qualities.

In this study, sponsorship in sports has been examined in four categories. These categories are: Individual athlete sponsorship, sports team sponsorship, sports organization (events) sponsorship and publication sponsorship.

Individual Athlete Sponsorship; the type of sponsorship, which is done by meeting the needs or the financial support of athletes who are successful in professional sports or amateur sports, or those who have a successful history in the sports they did in the past, is called individual sports sponsorship (Okay, 2012).

Sports Team Sponsorship; sports team sponsorship has a slightly different structure than sportsman sponsorship. With the sponsorship of the sports team, sponsorship occurs with a group of athletes and the name of a brand or company is presented with this sports team (Argan and Katırc1, 2015). The cost of sponsorship for sports teams is higher for the sponsoring institution. The main reason for this situation is that there are more people in the sports team and the need for the team is greater (Argan and Katırc1, 2015).

Broadcast Sponsorship; broadcasting sponsorship is defined as supporting the mentioned broadcasting program in cash or in kind in exchange for the name of the sponsoring company together with a special broadcasting program (Lardinioit and Quester, 2001; Tosun, 2003; Akyıldız and Marangoz, 2010).

Sports Organization (Event) Sponsorship; with the sponsorship of the sports organization, national sports leagues, national or international tournaments in the sports industry are sponsored.

In this study, it is tried to give information about sponsorship in general and sponsorship in sport in particular. In this context, a research on sponsorship and sponsorship in sports was carried out within the scope of the study.

In the period from 1980s until today, sponsorship has become one of the most important sources of income for athletes, sports clubs, sports organizations and institutions that manage sports, and has become the focus of the sports field.

As a result, sponsorship in sports has become one of the most effective communication tools used by organizations in almost every part of the world to reach their target audiences. As it can be understood from here, it is thought that sports sponsorship will continue its existence and development and increase its share in sponsorship as an indispensable tool of institutions, as a source of income that athletes, organizations, broadcasters and sports clubs will not want to lose.

Keywords: Sports, Public Relations, Sponsor, Sports Sponsorship, Types of Sports Sponsorship

Öz: Sponsorluk, ticari amaçlara ulaşabilmek için bir aktiviteye nakdi veya ayni destek sağlama şeklinde tanımlanabilir. Sponsorluk, kurumların yaptıkları iş ile doğrudan bağlantısı olmayan bir etkinliğe desteği aracılığıyla kurum veya marka için farkındalık yaratacak olumlu bir tanıtım meydana getirmeyi amaçlayan, 
pazarlama iletişiminde kullanılan önemli bir araçtır (Meenaghan,1983; Bennett,1999). Son yıllarda sponsorluğun uygulama alanları içerisinde spor alanı kendisine geniş bir alan bulmakta ve kendisini ön plana çıkarmaktadır. Bu çalışmanın amacı, sponsorluğun tarihsel gelişimini ve bireysel sporcuların, spor kulüplerinin, spor organizasyonlarının en önemli gelir kaynaklarını içinde barındıran sporda sponsorluk kavramını, türlerini ve kategorilerini incelemektir. Araştırmada nitel araştırma yöntemlerinden doküman toplama ve inceleme yöntemi aracılığıyla verilere ulaşılmıştır. Bu çalışmada veri toplamak için; kitap, makale, tez, internet sitesi ve benzeri veri toplama araçlarından faydalanılarak tarama yöntemi kullanılmıştır. Bu çalışmada genelde sponsorluk, özelde ise sporda sponsorluk hakkında bilgiler verilmeye çalışılmıştır. Bu bağlamda çalışma kapsamında sponsorluğa ve sporda sponsorluğa yönelik bir araştırma gerçekleştirilmiştir. Yapılan araştırmalar sonucunda sporda sponsorluk, dünyanın hemen hemen her yerinde kurumların hedef kitlelerine ulaşmakta kullandıkları en etkili iletişim araçlarından biri haline geldiği söylenebilir. Buradan da anlaşılacağı gibi spor sponsorluğunun, kurumların vazgeçilmez bir aracı, sporcuların, organizasyonların, yayıncı kuruluşların ve spor kulüplerinin kaybetmek istemeyecekleri bir gelir kaynağı olarak varlığını ve gelişimini sürdürmeye ve sponsorluk içindeki payını artırmaya devam edeceği düşünülmektedir.

Anahtar Kelimeler: Spor, Halkla İlişkiler, Sponsor, Spor Sponsorluğu, Spor Sponsorluğu Türleri

\section{Giriş}

Günümüz piyasa ortamlarında kuruluşlar, hedef kitleleriyle iletişim kurabilmek, onlarda kendilerine bir yer bulabilmek ve kurumsal hedeflerine ulaşabilmek için farklı yöntemlerden yararlanmaktadırlar. Bu farklı yöntemlerden ve pazarlama iletişimi araçlarından biri olan sponsorluk, kurumlar tarafindan sıklıkla kullanılan yöntemlerden birisi olmasına ve uzun zamandır varlığını sürdürmesine rağmen pazarlama iletişimi için yeni bir araç olduğu söylenebilir. Bu yönden, yeni yeni oturmaya başlayan bir pazarlama iletişimi aracı olarak görülebilir. Yoğun rekabet ortamının yaşandığı günümüzde, kuruluşlar tanınırlıklarını arttırmak için sıklıkla bu yöntemi kullanmaktadirlar.

Son yıllarda sponsorluk, kendisine geniş bir uygulama alanı bulmaktadır. Bu uygulama alanları içerisinde "spor" kendisini en çok ön plana çıkaran alandır. Bu doğrultuda araştırmada sporda sponsorluk kavramı derinlemesine, çeşitli türleriyle ve kategorileriyle incelenmek istenmiştir.

\section{Yöntem}

Bu çalışma, bireysel sporcuların, spor kulüplerinin ve spor organizasyonlarının en önemli gelir kaynaklarını kapsayan sporda sponsorluk kavramını incelemek amacıyla yapılmıştır. Araştırmada sponsorluk kavramının spor hayatlarındaki yeri ve önemini, sponsorluğa olan bakış açısını ve sporda sponsorluk olgusunun türlerini açıklamak amacıyla nitel araştırma yöntemi kullanılarak yapılmıştır. Araştırmada, doküman toplama ve inceleme yöntemi aracılığıyla verilere ulaşılmıştır. Bu çalışmada veri toplamak için; tez, kitap, makale, internet sitesi ve benzeri veri toplama araçlarından faydalanılmıştır.

\section{Sponsorluk}

Günümüz toplumu ve kuruluşlarında rekabet ve iletişim koşullarının değişmesiyle birlikte, iletişim karmasının içerisinde yer alan pek çok unsur da yeni sorunlarla karşı karşıya kalmıştır (Glogger, 1999; Okay, 2012). Kuruluşların dünya çapında büyük bir rekabet yaşamaları, ayrıca markaların çoğalması, geçici tüketici istekleri, multimedya araçlarının çoğalması nedeniyle bilginin çoğalması da (TV kanalları, sosyal medya, mobil telefonlar vb.) kuruluşların karşılaştıkları sorunlar olarak söylenebilir (Radicchi, 2014). Aynı zamanda bu gelişim çerçevesinde iletişimin kuruluşlar açısından taşıdığ 1 önem de giderek artmış, kuruluşlar hedef kitlelerine ulaşabilecek farklı iletişim yöntemlerinden ve araçlarından yararlanmaya başlamışlardır. Bu iletişim araç ve yöntemlerinden birisi de sponsorluktur (Okay, 2012). Sponsorluk, ticari amaçlara ulaşabilmek için bir aktiviteye nakdi veya ayni destek sağlama şeklinde tanımlanabilir. Kurumun yaptığı işle doğrudan bağlantısı 
olmayan bir etkinliğe desteği aracılığıyla kurum veya marka için farkındalık yaratacak olumlu bir tanıtım meydana getirmeyi amaçlayan, pazarlama iletişiminde kullanılan önemli bir araçtır (Meenaghan,1983; Bennett,1999). Sponsorluk, marka görünürlüğü, ürün veya hizmetlerin teşhiri, satışların artışı gibi özellikleri kazanmak için anlamlı bir araç olabileceği (Radicchi, 2014) ve tüketici gözünde belirli bir seviyede iyi niyet oluşturmak için kullanılabilecek iyi bir yöntem olabileceği söylenebilir (Turner vd., 2010).

Sponsorluğun geçmişine bakıldığında, Antik Yunanistan'a kadar dayandığı görülmektedir. Antik Yunanistan'da sponsorlar tarafından sosyal duruşlarını geliştirmek için, mali olarak desteklenen spor ve sanat festivalleri düzenlenirmiş (Sandler ve Shani, 1993; Masterman, 2007). M.Ö. $\quad$ 70- M.Ö. 8 yılları arasında yaşamış imparator August'un danışmanlığını yapan Romalı Diplomat Gaius Clinu Maecenas'ın adından hareketle ortaya çıkan ve sponsorluğun temelini oluşturan mesenlik, sadece başkalarını düşünen, kültürün ve toplum yaşamının desteklenmesini, iyi bir şeyin yapıldığını bilmekten başka bir beklenti ya da karşılık beklenilmeden yapılan bir faaliyeti (Walliser, 1995; Okay, 2012) belirtmek için kullanılan bir kavramdır. Mesenler, kişileri veya organizasyonları herhangi bir karşılık beklemeden desteklerler. Mesen, desteklemeyi kendisinin veya kuruluşunun adının desteklediği olayla anılmasa dahi yapar (Lock, 1988; Okay, 2012).

Sponsorluk, mütevazi bir geçmişten gelerek bugün gelişmiş bir iletişim aracına dönüşmüştür. 1970’lerde reklam, karşılıklı bir ikram ve yardım niteliğindeydi (Masterman, 2007). 1980'li yıllarda ise sponsorluk, pazarlamacılar arasında popülerleşmeye başladı, çünkü, sponsorluk promosyon için mükemmel destek elementi haline gelmişti (Brassington ve Pettitt, 2000). Şimdilerde bir dizi pazarlama ve kurumsal iletişim hedeflerine ulaşma yoluna dönüşmüştür. Günümüzde satışları arttırmanın yanında faydalı marka ilişkileri ve farkındalık geliştirmek, kurum imajı için farkındalık yaratmak ve organizasyonel iç ilişkileri geliştirmek için de kullanılmaktadır (Masterman, 2007). Var olan tutundurma faaliyetlerinden hiçbirine sponsorluğa bakıldığı kadar sıcak ve yakın olunmamıştır (Ferreira vd., 2008; Baş, 2008).

Sponsorluk, sponsor ile sponsor olunan kuruluş arasında bir alışverişin olduğu bir stratejik iletişim aracı haline gelmiştir. (Quester ve Bal, 2013). Sponsor olan kurum açısından bakınca, araştırmalara göre, sponsorluk yatırımının marka farkındalığını, marka imajını, marka sadakatini ve bir şirketin mali performansını olumlu etkilediği kanıtlanmıştır (Levin vd., 2001; Gwinner ve Eaton,1999; Levin vd., 2004; Mazodier ve Rezaee, 2013). Spor, sanat ve eğlence ile ilgili kuruluşlarda sponsorluk marka pazarlamasında temel elementlerden olmuştur. 1987 yılında sponsorluk harcamaları 5,6 milyar dolar olduğu bilinmektedir (Hino ve Takeda, 2019). Şekil 1 incelendiğinde global sponsorluk piyasasının 2018 yılında 65,8 milyar dolarlık bir harcama gerçekleştirdiği görülmektedir. 2018 yılı ile 2017 yılı kıyaslandığında 4.94\% artış olduğu, 2007 yılı ile kıyaslandığında ise $73,62 \%$ artış olduğu anlaşılmaktadır (https://rtrsports.co.uk/blog/growthsponsorship-global-spending/, 2019). 1987 ile 2018 yıllarının kıyaslanması sonucu 1075\% oranında bir artış olduğu söylenebilir. 
Şekil 1. 2007-2018 Yılları Arası Dünya Çapındaki Sponsorluk Harcamaları (Milyar Dolar)

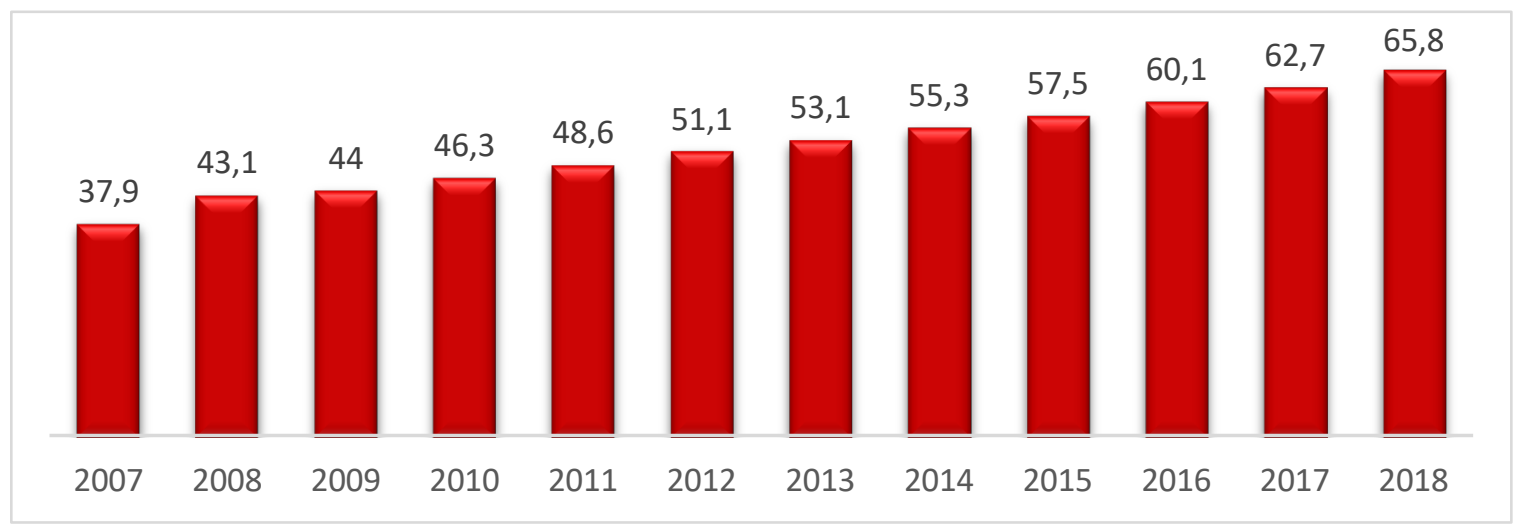
26.04.2019)

Kaynak: https://rtrsports.co.uk/blog/growth-sponsorship-global-spending/ (Erişim Tarihi:

Sponsorlukta uzun vadeli bir ilişki, sponsorluğun rekabetçi bir avantajın kaynağı olması potansiyelini arttırır. Örneğin, sponsorluğun süresi ne kadar uzunsa, tüketicinin hafizasında marka ile ürünün arasında güçlü bir bağlantı kurulması olasılığı bir o kadar artar (Cornwell ve Humphreys, 2013). Bu araştırmaya uygun olarak, sezonluk bilet sahipleri ile yapılan birçok araştırmaya göre, sponsorluğun süresi uzadıkça sponsorun ismini hatırlama şansını yükselttiği hatta sponsorluk bittikten sonra bile hatırlanmasını sağlayabildiği söylenebilir (McDonald ve Karg, 2014). Poon ve Prendergast (2006) sponsor ve sponsor olunan arasındaki uyumun sponsorluğun olumlu sonuçlar yaratması açısından önemli olduğunu söylemiştir. Diğer araştırmacılar ise, yanlış sponsor seçmenin hedeflere ulaşmayı engellediğini, bu yüzden partnerler arasındaki uyumun sponsorluk aktivitesinde önemli bir rol oynadığını söylemişlerdir (Gordon ve Cheah, 2014).

Son yıllarda sponsorluğa olan ilgide ve spor endüstrisine iş dünyasının katılımında artı̧̧ olduğu görülmektedir (Morgan vd., 2014). Bu doğrultuda sponsorluk anlaşmaları, en hızlı gelişen kurumsal pazarlama aracı halini aldığı söylenebilir (Cunningham vd., 2009). Ek olarak Kuzey Amerika'da yapılan bir araştırmaya göre; ticari kuruluşların sponsorluk harcamalarının \%70'inin spor organizasyonlarına (Bkz. Şekil 2) yapıldığı belirlenmiştir (Jensen ve Cobbs, 2014).

Şekil 2. Kuzey Amerika 2018 Y11 Öngörülen Sponsorluk Yüzdeleri

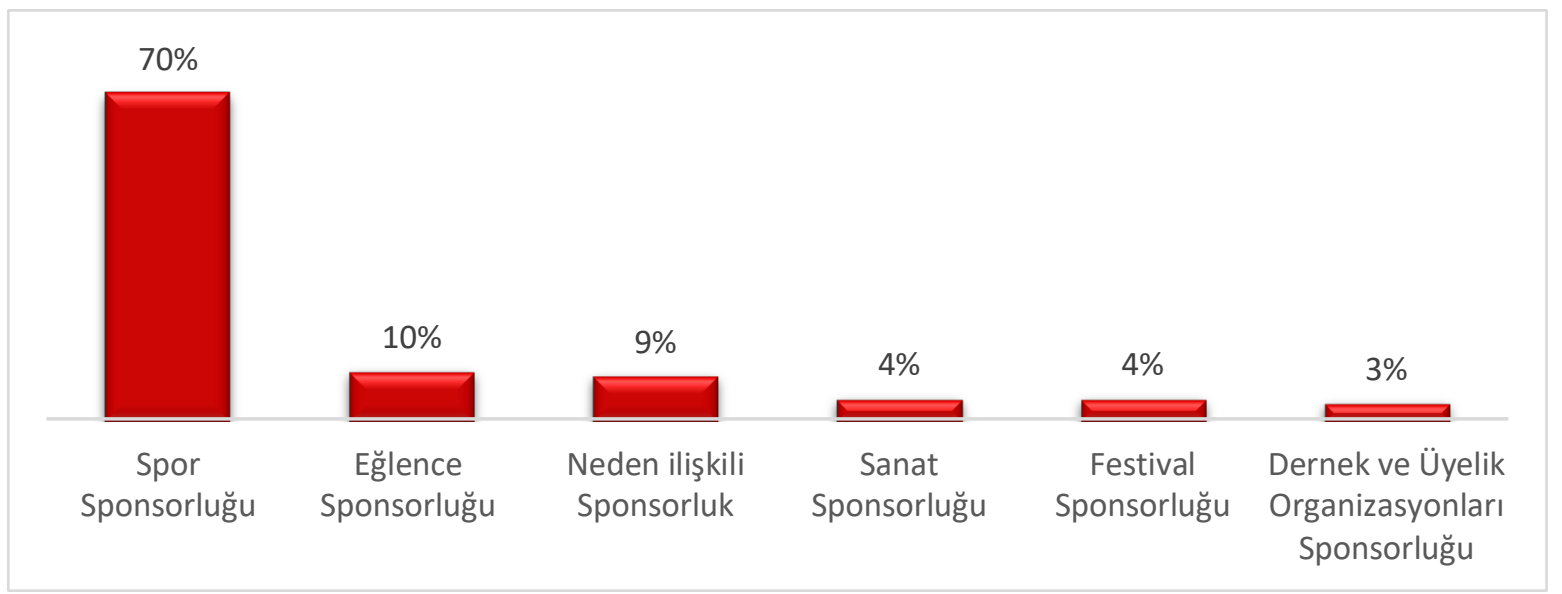

Kaynak:http://www.sponsorship.com/IEG/files/f3/f3cfac41-2983-49be-8df63546345e27de.pdf (Erişim Tarihi: 26.04.2019) 
Yukarıdaki tüm bu bilgiler 1şığında bu çalışmada, sporda sponsorluğun derinlemesine incelenmesi amaçlanmaktadır.

\section{Sporda Sponsorluk}

Kurumsal iletişim harcamalarının büyük bir kısmını oluşturmakta olan sponsorluk harcamalarında dünya çapında bir artış meydana gelmiştir (Radicchi, 2014). Spor alanı, sponsorluk aracının kullanıldığı en yaygın alan haline gelmiş ve sponsorluk yatırımlarının aslan payını almaya başlamıştır (Collet ve Fenton, 2011). Bu bağlamda şirketler, spor kulüpleri ile birlikte çalışarak, belirli nitelikleri temsil eden markalar ile ilişki kurmaya başlamışlardır. Seyirciler, müşteriler, tüketiciler ve kullanıcılar sponsorun logosunu ve diğer sembollerini etkinlik, oyun, maç, oyuncu vb. şeyler içinde gömülü olarak bulurlar ve aktivite ile sponsoru ilişkilendirirler (Jobber, 2007). Cornwell vd. (2001)'ne göre, “Aynı spor etkinliğinde bir sponsorun ismini görmek, tüketiciye ürün ve sponsorluk ilişkisinin önemi hakkında düşünme yönünde birçok firsat sunar ve böylece hafizada güçlü bağlar yaratır”. Bu bağlantı ile spor kulüpleri ve şirketler bir ortak yaşam alanı yaratır ve karşılıklı olarak artan gelirler sağlayacak bir iş birliği için istikrarlı şartlar meydana getirirler (Jobber, 2007).

Dünyada spor alanında sponsorluk yapan şirketlerin çoğunluğu içecek (Pepsi, Coca-Cola, Redbull vb.), otomotiv (Ford, Hyundai, Jeep, Chevrolet, Toyota, Honda, General Motors, Volkswagen vb.), hava yolu (Turkish Airlines, Qatar Airways, Air Asia, Etihad Airways, Fly Emirates, Virgin Atlantic vb.), finans (Barclays, QNB, UniCredit, HSBC, American Express, Standart and Chartered vb.), bahis (ManBetX, Dafabet, fun88, Betway vb.) ve spor giyim (Nike, Under Armor, Adidas, Puma, Reebok, Umbro, Lotto vb.) sektöründe faaliyet göstermektedirler.

Türkiye'de ise spor alanında sponsorluk yapan şirketlerin çoğunluğu yiyecek (Selva, Arbella, Yayla, Marmara Birlik, Trakya Birlik, Burger King, Ülker, Seyidoğlu, Koska vb.), inşaat (Atış Yapı, Nef, Çevik Beton vb.), bahis (İddaa, Sportoto, nesine.com, bilyoner.com vb.), sağlık (Anadolu Hastanesi, Medicana, Memorial, Acıbadem, Liv Hospital vb.), içecek (Aroma, Uludağ, Erikli, Çaykur, Redbull vb.), bankacılık ve finans (Ziraat Katılım, Akbank, Denizbank, Aktifbank, Odeabank, QNB Finansbank, HDI Sigorta, Doğa Sigorta, Anadolu Sigorta vb.) otomotiv (Doğuş Otomotiv, Audi, Volvo, Tofaş Türk Otomobil Fabrikası vb.), hazır giyim (Kiğglı, Damat Tween, İmza, D'S Damat, Altın Yıldız vb.) ve petrol (Opet, Aytemiz, Lukoil, Mogaz vb.) sektöründe faaliyet göstermektedirler.

Alan yazın incelendiğinde sporda sponsorluğun üç (bireysel sporcu, spor takımı ve spor organizasyonu sponsorluğu) ya da dört (bireysel sporcu, spor takımı, spor organizasyonu ve yayın sponsorluğu) türde incelendiği görülmektedir. Bu çalışmada sporda sponsorluğun dört türü incelenmiştir. Bu türler: Bireysel sporcu sponsorluğu, spor takımı sponsorluğu, spor organizasyonu (etkinlikleri) sponsorluğu ve yayın sponsorluğudur. Değinilen bu bilgilerin alan yazını zenginleştirme anlamında önem arz edebileceği söylenebilir.

\subsection{Bireysel Sporcu Sponsorluğu}

Profesyonel veya amatör sporcuların yaptıkları spor dallarında başarılı olanlar içerisinden, geçmişte yaptıkları spor dallarında başarılı bir geçmişi olanların veya gelecekte başarılı olabilme ihtimali olan sporcuların gereksinimlerinin karşılanmasıyla veya maddi yönden desteklenmesiyle yapılmakta olan sponsorluk türüne bireysel sporcu sponsorluğu denilmektedir (Okay, 2012). Kurumun veya markanın belirlediği hedeflere, sponsor olunan sporcular aracılığıyla daha hızlı erişmek ve ürünlerin kullanımı veya reklamları aracılığıyla daha çok kişiye ulaşmak maksadıyla bireysel sporculara sponsorluk desteği verilmektedir (Öztürk, 2013).

Bireysel sporcu sponsorluğunun, marka bilinirliğine, marka imajına ve şirket imajına katkı sağlamada yadsınamaz bir rol oynadığı söylenebilir (Dumont, 2016). Sponsor, yapılan spor olayının ününe veya sporcunun yaptığı spor dalında elde ettiği başarısıyla daha çok tanınmışlık kazanabilir 
(Argan ve Katırc1, 2015). Bununla beraber, bireysel sporcuların sponsorluğunu gerçekleştirerek kendi tanıtımını gerçekleştirebilir, reklamını yapabilir ve ulaşmayı hedeflediği kitle üzerinde etkili olabilecek sporcuları kurum ile ilgili olumlu bir ilişkinin kurulması için değerlendirebilir (Baş, 2008).

Günümüzde önemli sponsorluk anlaşmaları yapan sporcular arasında NBA'deki (National Basketball Association) basketbol oyuncuları da yer almaktadır. Bu duruma "Michael Jordan" etkisi denebilir. 1997 y1lında Michael Jordan, Nike, McDonald's, Gatorade ve Wheaties gibi şirketlerin sponsorluğundan 47 milyon dolarlık kazanç elde etmesiyle yukarıda bahsedilen durum oluşmuştur (Schwarz ve Hunter, 2008). Bireysel sporcu sponsorluğuna farklı birkaç örnek verilecek olursa; golf 'de başarılı bir kariyere sahip olan Tiger Woods'un American Express, General Motors, Nike ve Rolex gibi markalar tarafından desteklenmesi; tenis sporcusu Maria Sharapova'nın Canon, Colgate ve Motorola, gibi farklı sponsorlar ile yaptıkları yıllık anlaşmalar (Sports Marketing, 2007; Öztürk, 2013) Türkiye'den ise Levi's ve Quantum markalarının dünya rekortmeni milli sporcu Şahika Ercümen'e sponsor olması söylenebilir. Şekil 3'de bazı sporcuların gerçekleştirmiş oldukları bireysel sponsorluk anlaşmalarının değerine yönelik bilgiler verilmiştir.

Şekil 3. Bazı Sporcuların Yapmış Olduğu Toplam Sponsorluk Anlaşması Değerleri (Milyon Dolar)

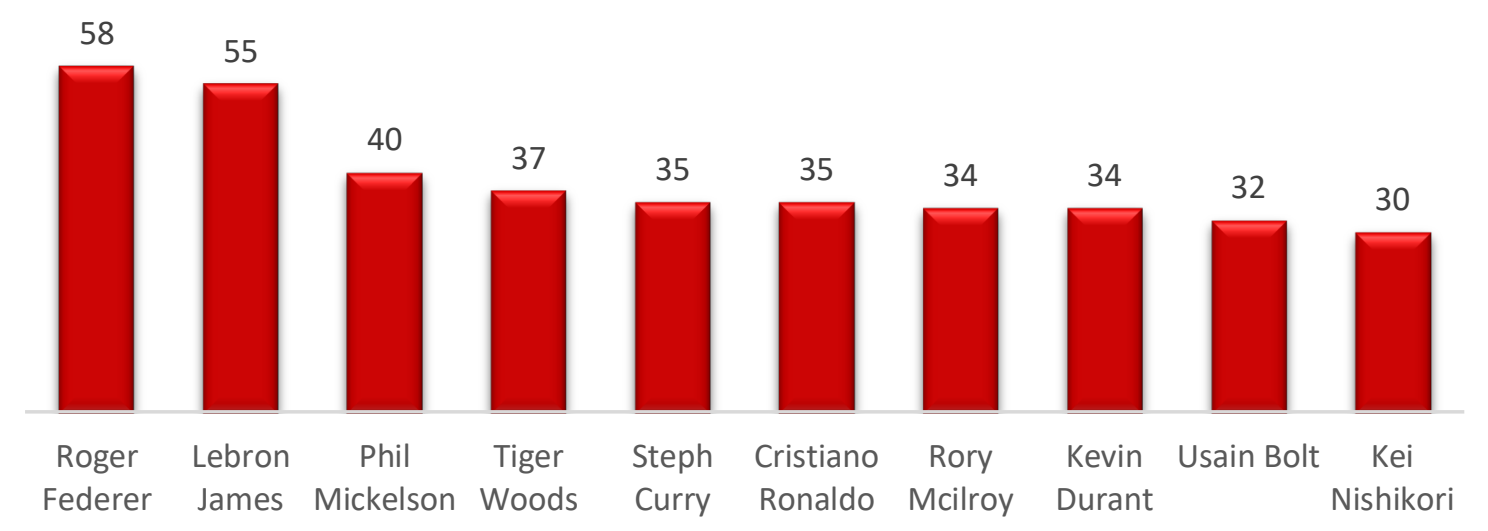

Kaynak: https://www.pledgesports.org/2017/11/biggest-athlete-sponsorship-deals-insport-2/ (Erişim Tarihi: 26.04.2019)

Bireysel sporcu sponsorluğu yapmanın bazı riskleri vardır. Örneğin, sponsor olunan sporcunun müsabakalarda başarısız olması, doping, uyuşturucu kullanması veya toplumun tepkisine neden olabilecek olaylara karışması, sponsor olan kurumun ismini olumsuz olarak etkileyebilir (Argan ve Katırc1, 2015).

\subsection{Spor Takımı Sponsorluğu}

Spor takımı sponsorluğu, sporcu sponsorluğuna göre biraz farklı bir yapıya sahiptir. Spor takımı sponsorluğu ile bir grup sporcuyla sponsorluk gerçekleşir ve bir markanın veya firmanın adı bu spor takımıyla beraber sunulur. Kurumlar spor takımı sponsorluğunu çeşitli nedenlere dayanarak tercih edebilirler. Zira bu sponsorluk türünde daha büyük bir etki meydana gelebilmektedir. Bununla beraber, spor takımlarına yapılan sponsorluğunun maliyeti, sponsor olan kurum için daha yüksektir. Bu durumun temel nedeni spor takımında daha fazla kişinin olması ve takımın ihtiyacının daha büyük olmasından kaynaklanmaktadır (Argan ve Katırc1, 2015).

Bireysel sporcu sponsorluğuna göre takım sponsorluğunun yapılması daha az risk barındırır. Spor takımlarının seçiminde de sponsor olan kurumun ulaşmayı hedeflediği kitlelerle spor takımının hitap ettiği hedef kitle arasında bir uyumun olması gereklidir (Okay, 2012). 
Takım hâlinde yapılan sporlar kitle iletişim araçlarında daha çok yer bulurlar, dolayısıyla daha fazla farkındalık yaratılır. Özellikle futbol müsabakalarının her hafta gerçekleştirilmesi ve kimi müsabakaların televizyondan canlı yayınlanması sebebiyle farkındalık oranları daha yüksek olabilmektedir. Belirli markaların basın ve televizyonda yer bularak hedef grupları tarafindan görülebilmesi ve hedef gruplarıyla daha kolay bir iletişim kurulabilmesi sebebiyle kurumlar takım sponsorluğunu seçer. Özellikle de takımlar çeşitli ulusal ve uluslararası spor organizasyonlarına katıldıkça sponsorların adları daha geniş bir coğrafyada duyulmaya başlar (Öztürk, 2013). Böylelikle sponsorlar uluslarası alanda tanınırlık elde ederler.

Spor takımları, finans faaliyetlerinde sponsorluktan çeşitli şekillerde yararlanmaktadır (Kim vd., 2011). Bunlara birkaç örnek verilecek olursa; Barcelona, Japon çevrimiçi alışveriş sitesi Rakuten ile yaptığ 4 yıllık forma sponsorluğu antlaşması ile toplamda 220 milyon avro gelir elde etmektedir (http://tr.beinsports.com/fotogaleri/iste-en-pahali-sponsorluk-anlasmalari, 2019). Manchester City ile Puma arasında yapılan ekipman ve forma sponsorluğu ile 10 yılda toplamda 650 milyon sterlin kazanacak (https://www.sportsjoe.ie/football/man-city-kit-deal-with-puma-194615, 2019). Beşiktaş, Vodafone ile 2014-15 sezonu ile başlayan forma reklamı anlaşmasını iki tarafın yapmış olduğu sözleşmede yer alan uzatma seçeneğini değerlendirerek 2019-20 ve 2020-21 sezonları için toplam 10 milyon Dolar + katma değer vergisi tutarı karşıılığında 2 sezonluğuna daha uzattı. Beşiktaş Jimnastik Kulübünün Vodafone ile gerçekleştirdiği forma sponsorluğunun değeri 7 y1l için toplam 35 milyon Dolar'a ulaşacak (http://www.fotospor.com/haber-besiktas-besiktasa-7-yilda-35-milyondolar-335177, 2019). Trabzonspor kulübü 14 Temmuz 2016'da forma sponsorluğu için anlaştığ1 QNB firmasından 3 yıl için 7,5 milyon dolar + KDV değerinde bir gelir elde etti (https://blog.anasponsor.com/trabzonspor-qnb-sponsorluk-anlasmasinin-detaylari/, 2019 ). Bahsedilen duruma örnek olarak verilen "Avrupa'nın beş büyük liginde en yüksek sponsorluk gelirine sahip olan futbol kulüplerinin 2018 y1lı sponsorluk gelirleri ve anlaşma sayılarına" dair bilgiler Şekil 4'te verilmiştir. Şekil 4'te verilen bilgilere göre sponsorluk gelirleri ve sözleşme sayıları incelendiğinde, spor kulüplerinin popülaritesinin sponsorluk sözleşmelerinin parasal değeri üzerinde etkisi olduğu söylenebilir.

Şekil 4. Avrupa'nın Beş Büyük Liginde En Yüksek Sponsorluk Gelirine Sahip Futbol Kulüplerinin 2018 Yılı Sponsorluk Gelirleri ve Anlaşma Sayıları (Milyon Avro)

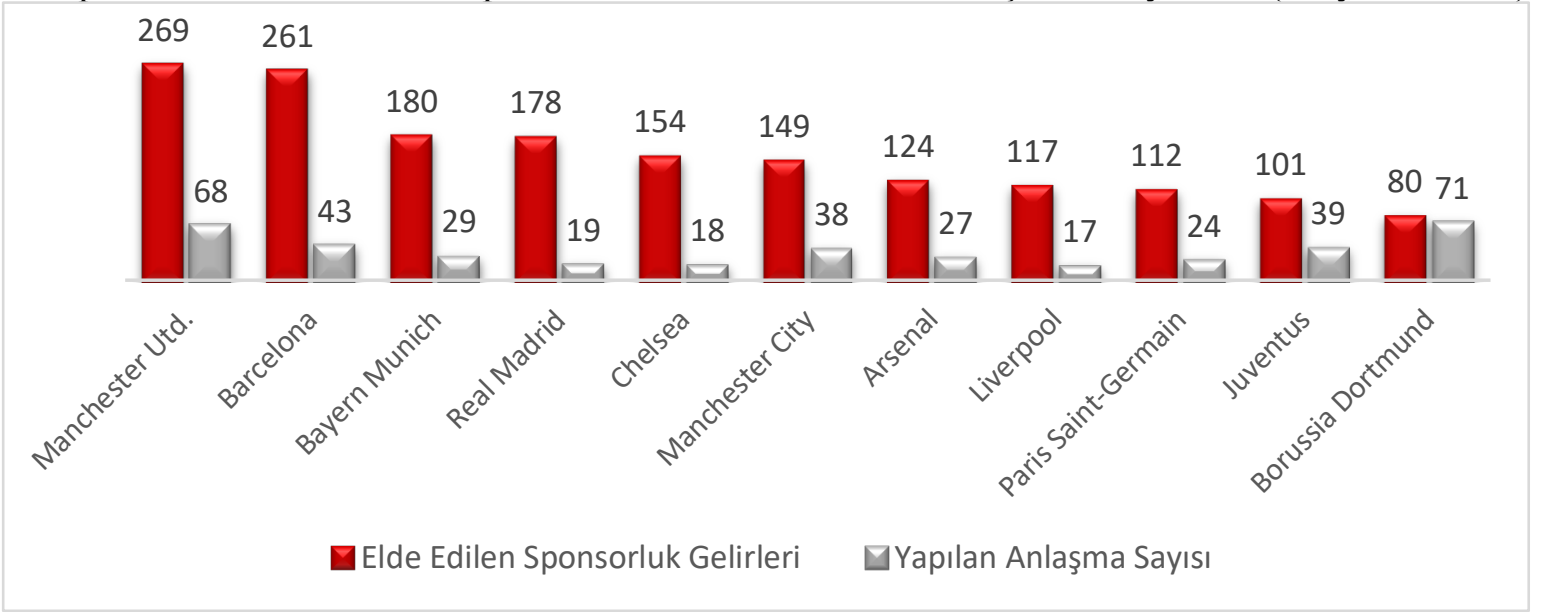

Kaynak: https://sponsorship.org/csms-2018-football-super-spenders-report/ (Erişim Tarihi: 26.04.2019)

Bu bilgilere ek olarak motor sporları alanının zirvesi olan Formula 1 yarış organizasyonunda mücadele eden takımların bütçelerinin \%70'inin sponsorluk gelirlerine dayandığı bilinmektedir (Jensen ve Cobb, 2014). 


\subsection{Yayın Sponsorluğu}

Yayın sponsorluğu sponsor olan firmanın adının özel bir yayın programıyla beraber anılması karşılığında söz konusu yayın programının nakdi veya ayni olarak desteklenmesi şeklinde tanımlanmaktadır (Lardinioit ve Quester, 2001; Tosun, 2003; Aky1ldız ve Marangoz, 2010). Bu sponsorlukta amaç, doğrudan hedef kitleye ulaşmak için yapılan kitle iletişim araçlarına destekte bulunarak spor kamuoyunda olumlu izlenim birakmaktır (Soyer, 2003; Aktan, 2017). Böylelikle yayın sponsorluğunun sponsorlara ekstra etki sağladığı da söylenebilir (Walliser, 2003).

Yayın sponsorluğunun, yazılı basın, radyo, televizyon veya internet reklamlarını bünyesinde barındırdığ1 söylenebilir (Frederick ve Patil, 2010). Bu sponsorluğun önemli bir kısmını oluşturan spor yayınları sponsorluğu, televizyon ve radyo yayınlarına desteğin farklı şekilde ifadesi olarak açıklanabilir. Bir başka deyişle radyoda ya da televizyonda yayınlanan spor programlarına, bu programa yorumcu olarak katılan kişilere yayın sponsorluğu şeklinde destekte bulunulması olarak da açıklanabilir. Özellikle özel televizyon ve radyo kanallarının artması bu alandaki sponsorlukların sayısını artırırken, yayın sponsorluğu bütçesini de aynı oranda artırmaktadır (Şahin vd., 2003; Çavuşoğlu, 2011).

Yayın sponsorluğunun şöyle bir dezavantajı söz konusudur: Yayın sponsorluğu, organizasyon sponsorluğu gibi insanları eğlendiren bir sponsorluk türü değildir. Bununla beraber tüketicide etki bırakma anlamında organizasyon sponsorluğu kadar başarılı olmadığı da söylenebilir (Mason, 2005).

\subsection{Spor Organizasyonu (Etkinliği) Sponsorluğu}

Spor organizasyonu sponsorluğu ile spor endüstrisi içerisinde yer alan ulusal spor liglerine, ulusal veya uluslararası turnuvalara sponsorluk yapılır.

Sponsor olan kurumla organizasyon arasındaki güçlü uyumun, organizasyonun sahip olduğu olumlu bakışın kuruma aktarılmasında önemli bir rolü vardır (Rifon vd., 2004; Başar, 2018). Örneğin spor ayakkabı üretimi gerçekleştiren bir kurumun atletizmle ilgili bir turnuvaya sponsor olması uyumluluk olarak algılanırken, alkollü içecek üretimi yapan bir kurumun sponsor olması uyumsuzluk olarak algılanabilir (Akyıldız ve Marangoz, 2008). Sponsor firma ile organizasyon arasındaki uyumun ne kadar önemli olduğunun verilen bu örnekten anlaşılacağı düşünülmektedir.

Spor organizasyonu (etkinliği) sponsorluğunun kurumsal sponsorlar için uzun dönemli sponsorluklardan ekonomik açıdan daha faydalı olduğu söylenebilir. Çünkü organizasyonla ilgili büyük medya ve reklam faaliyetleri sonucunda sponsor olan kurumun kazancı da büyük olur (Schwarz ve Hunter, 2008). Sponsorlukta hem sponsor olan kurum hem de sponsorluk desteğini alan organizasyon, değerlerini birbirlerine aktardıkları bir ilişki içinde bulunmaktadırlar. Organizasyonun hedef grubu organizasyon süresince sponsor olan kurumun adını, logosunu ve öteki markalarına dair uyaranları görür ve bunların etkisine maruz kalırlar. $\mathrm{Bu}$ durumun bir sonucu olarak sponsor olan kurumu ve organizasyonu birbiriyle ilişkilendirmeyi öğrenir ve sponsor olan kurumun marka farkındalığı artar (Dumanlı Kürkçü, 2015). Bu şekilde, tüketicilerin zihinlerinde organizasyon ile sponsor olan kurum arasında bir bağ meydana getirilir (Erdoğan ve Kitchen, 1998; Özer, 2011; Başar, 2018).

Mason (1999) kurumsal sponsorlukların, profesyonel liglerin en önemli gelir kaynaklarından birisi olduğunu ve şirketlerin yoğun harcamalarının da profesyonel lig endüstrisinin gelişmesinde ve büyümesinde büyük bir etki yarattığını belirtmektedir. Türkiye Futbol Federasyonu ve Digitürk tarafindan oluşturulan Türkiye Profesyonel Futbol Süper Ligi isim hakk1 sponsorluk modeli, “Turkcell Süper Lig” adıyla Türkiye'de ilk olarak Turkcell tarafından uygulanmıştır (Öztürk, 2013). Sonrasında da Türkiye Profesyonel Futbol Süper Ligi isim sponsoru Spor Toto olmuştur. Türk Hava Yolları (THY), Avrupa kıtasının en büyük basketbol organizasyonu olarak bilinen Euroleague Basketball ile 5 yılı opsiyonlu olmak üzere 10 y1l süreli isim hakk1 sponsorluğu için anlaşma 
yapmıştır (https://www.istekobi.com.tr/kobi-bilgi-merkezi/haberler/thy-euroleague-in-isimsponsoru-oldu-h5546.aspx, 2019). Türk Hava Yolları, daha sonra sözleşmedeki opsiyonu kullanarak sponsorluk anlaşmasını 2020 yılına kadar uzatmışı̧ı (https://www.trtspor.com.tr/haber/basketbol/thy-euroleague/2020-yilina-kadar-thy-56178.html,

2019). Rio de Janerio'da gerçekleşen 2016 Yaz Olimpiyat Oyunlarında sponsorluk gelirlerinden yaklaşık 848 milyon dolar (https://www.statista.com/statistics/274449/marketing-revenue-ofolympic-games-from-domestic-sponsorships/, 2019), 2014 Sochi kış olimpiyat oyunlarında 1,3 milyar dolar değerinde sponsorluk geliri elde edilmiştir (Foster vd., 2016). Pepsi ile Amerikan Futbol Ligi (NFL) arasında 2011 yılında 2,3 milyar dolar değerinde 10 y1llık bir sponsorluk anlaşması imzalanmıştır (Rowe vd., 2019). Çin Futbol Birliği ile Nike arasında 2015 yılında gerçekleştirilen ve 11 yıl sürecek olan anlaşma ile Çin Futbol Birliği yıllık ortalama 16 milyon dolar sponsorluk geliri elde edeceği söylenebilir (Foster vd., 2016). Bu örneklerden de anlaşılacağı gibi sponsorluk hem profesyonel liglerin gelişmesinde hem de sponsor olan kuruluşların yaptıkları yüksek harcamaların karşılığı olarak gerek ulusal gerek uluslararası anlamda isimlerini duyurmada büyük bir etkisi olduğu söylenebilir.

Spor organizasyonu sponsorluğunu gerçekleştiren bir kurumun, sponsorluk anlaşmasıyla oluşturulmuş olan haklarından ayrı olarak kazanabileceği faydalar şu şekilde olabilir (Argan ve Katırc1, 2015):

- $\quad$ Spor etkinliğinin gerçekleştirileceği yere saha kenarı reklamları yerleştirmek.

- Sponsor olan firma tarafindan verilmiş olan spor teçhizatı ve kullanılan transfer araçları üzerinde sponsor olan kurumun reklamının bulunması.

- Ulusal veya uluslararası, özel veya resmi, gerçekleştirilen spor etkinliklerinin sponsoruyla bu etkinliklerin ismini birleştirme imkânı.

- G Görülebilecek yerlere kurumun ismini veya ürünün reklamını koyma imkânı.

\section{Spor Sponsorluğunun Sınıfları}

Spor sponsorluğu nakdi ve ayni sponsorluk olmak üzere iki sınıftan oluşmaktadır. Sponsor olan kurumların yaptıkları finansal türde (parasal) olan desteklere nakdi sponsorluk denir. Ayni sponsorluk ise sponsor kurumların yaptıkları ürün veya hizmet desteği sunulmasına denir (Carrillat ve d'Astous, 2012). Ayni sponsorluk sınıfına, sponsor olunana bilgi yardımı yapmak, eğitim almış tecrübeli çalışanını sponsor olunanın hizmetine sunmak veya sponsor olunan faaliyetle alakalı her çeşit organizasyon hizmetini gerçekleştirmek gibi işler de dahildir (Baş, 2008).

\section{Spor Sponsorluğunun kategorileri}

Spor sponsorluğunun dört farklı kategorisi vardır. Bunlar; özel (ayrıcalıklı) sponsorluk, ana sponsorluk, resmi malzeme tedarikçisi ve yardımcı sponsorluktur.

\section{1.Özel (Ayrıcalıklı) Sponsorluk}

Bu sponsorluk türünde belirli bir spor organizasyonuna tek başına sponsor olma durumu söz konusudur. Argan ve Katırcı'nın (2015) aktarımına göre özel sponsorluğun üç tane üstünlügü vardır. Birincisi, özel bir sponsor adını bir olayın başlığ 1 şeklinde, takım adı şeklinde veya adını kupada kullanabilir. İkinci olarak, sponsor olan kurum promosyonel gayeler için ilgili platformun kullanım hakkına tek başına sahiptir. Bu durum firmaya diğer iletişim araçlarını, reklamlarını, odaklanmayı en üst seviyeye çıkarmayı muhtemel kılar ve diğer sponsorların ihtiyaçlarıyla ilgili olmayan farklılaştırma yapma imkânı tanır. Üçüncüsü, özel bir sponsorluk ile bütünleşen saygınlık, sponsor olan kurumun ürünlerine bir değer katma imkânı sunabilir. Örneğin tenis sporunun hayranları, kendi spor dallarına destek olan bir firmaya karşı pozitif duygular hissetmesini sağlayabilir (Brooks, 1994; Argan ve Katırcı, 2015). Özel sponsorluğun en önemli dezavantajı spor organizasyonu için mali tek 
kaynak olmasıdır. Eğer beklenmeyen maliyetler oluşursa organizasyonun gerçekleşmesi sponsorun finansal desteğini arttırmasına bağlıdır. Eğer desteklenen spor olayıyla, takımla ya da sporcu ile alakalı negatif gelişmeler oluşursa özel sponsor kayda değer miktarda bir tutar kaybedebilir ve imajında olumsuz anlamda ciddi sorunlar oluşabilir (Öztürk, 2013). Özel sponsorluğa Ziraat Bankası'nın sponsorluğunda gerçekleştirilmekte olan Ziraat Türkiye Kupası verilebilir.

\subsection{Ana Sponsorluk}

Ana sponsorluk, sponsorluk yapılan projeyi sahiplenmek isteyen kurumların değerlendirdiği bir sponsorluk kategorisidir. Ek olarak, bir projenin birçok ana sponsoru olabilir (https://anasponsor.com/sponsorluk-cesitleri-nelerdir/, 2019). Birçok ana sponsor olması halinde bile bir ana sponsor çoğunlukla imtiyazlı haklara sahip olmaktadır. Bir ana sponsor adının spor olayının adının içinde bulunmasını ve adının televizyonda ve basında olay ile ilişkili olarak bahsedilmesi görüşülebilir (Öztürk, 2013). Değinilen bu durum, ana sponsora özel bir izlenim sağlar. Seyirci veya katılımcılar, olayı veya takımı ana sponsorun ismi veya ürünü ile özdeşleştirmeye başlar (Brooks, 1994; Argan ve Katırc1, 2015). Ana sponsorluğa, Milka ile Türkiye Kayak Federasyonu ve milli takımlar arasında 2019 yılında gerçekleştirilen ana sponsorluk anlaşması örnek olarak verilebilir (https://www.tkf.org.tr/milka-ile-sponsorluk-anlasmasi-imzalandi/, 2019).

\subsection{Yardımcı Sponsorluk}

Yardımcı sponsorluk, ürün kategorilerine göre ayrılmış birkaç firmanın yer aldığı ikinci düzey sponsorluk türüdür (Öztürk, 2013). Genellikle ana sponsorun arkasında daha küçük finansal sözleşme yapan sponsor markları kapsamaktadır. Dolayısıyla riski az olduğu için sponsorlukta deneyimi olmayan markalar tarafindan tercih edilmektedir. Fakat yardımcı sponsorların tutunması bazen zordur. Çünkü spor faaliyetindeki hakları yetersiz görüp veya medyada yeterince tanıtım elde edemediği için sponsorluktan çekilebilmektedirler (Danyichuk, 2000; Aktan, 2017). Yardımc1 sponsorlukta verilen hizmetlere otel konaklamaları, seyahat acentesi hizmetleri, araç ile taşıma hizmetleri ve ofis ekipman destekleri örnek olarak verilebilir.

\subsection{Resmi Malzeme Sponsorluğu}

Resmi malzeme sponsorluğu, yardımcı sponsorluğun özel bir biçimidir (Argan ve Katırcı, 2015). Bu sponsorluk türünde sponsor, sporcuya veya spor kuruluşuna sportif faaliyetlerin gerçekleştirmesi için malzeme tedarikinde bulunur (Jensen vd., 2016). Maddi yönden, ürün veya hizmet sunarak sponsor olan kurumların yaptığı sponsorluk türü olarak da tanımlanabilir (https://anasponsor.com/sponsorluk-cesitleri-nelerdir/, 2019). Repucom'un hazırlamış olduğu yıllık Avrupa Futbol Takımları Tedarikçi Raporuna göre, İngiliz Premier Lig takımlarının malzeme sponsorlarından 163 milyon Avro kazandığını belirlenmiştir (Repucom, 2014; Jensen vd., 2016).

\section{Sonuç}

$\mathrm{Bu}$ çalışmada genelde sponsorluk, özelde ise sporda sponsorluk hakkında bilgiler verilmeye çalışılmıştır. Bu bağlamda çalı̧̧ma kapsamında sponsorluğa ve sporda sponsorluğa yönelik bir araştırma gerçekleştirilmiştir.

Sponsorluk, günümüzde dünyanın hemen hemen her yerinde kurumların hedef kitlelerine ulaşmakta kullandıkları en etkili pazarlama iletişimi araçlarından birine dönüşmüştür.

Kurumlar, sponsorluğu birçok nedenle kullanmaktadırlar. Bunlardan bazıları şu şekilde sıralanabilir: Satış ve pazarlama hedeflerine ulaşmak, kendilerinin veya markalarının bilinirliğini ve farkındalığını arttırmak, rakip kuruluşlar karşısında bir adım öne geçebilmek için sponsorluğu kullanmaktadırlar. $\mathrm{Bu}$ nedenlerden dolayı sponsorluk, kurumların rakipleri karşısında avantajını devam ettirmede veya dezavantajını ortadan kaldırmada, pazar payını korumada veya arttırmada faydası olabilecek potansiyeli olan değerli bir araç haline geldiği söylenebilir. 
Spor, hitap ettiği geniş izleyici kitlesinden dolayı pek çok kurum için bir cazibe merkezine dönüşmüş, popülaritesi olan bir alandır. Bu popülarite ile birlikte sponsorluk türleri arasında spor sponsorluğunun etkisinin artmasıyla birçok firma bu sponsorluk türüne yönelmiştir. Günümüzde spor sponsorluğu bireysel sporcu, spor takımı, spor organizasyonu ve yayın sponsorluğu türleri ile sporcuların, spor kulüplerinin, spor organizasyonlarının ve sporu yöneten kurumların en önemli gelir kaynaklarından biri halini gelmiş ve spor alanının odak noktası olmuştur. Spor sponsorluğu ile sponsor olan kurumlar aracılığıla sporculara, organizasyonlara, yayıncı kuruluşlara ve spor kulüplerine önemli miktarlarda gelirler sağlanmaktadır. Elde edilen sponsorluk gelirlerinin nakdi değerinin belirlenmesinde, sponsor olunanın popülaritesinin etkili olduğu söylenebilir.

Tüm bu bilgiler doğrultusunda spor sponsorluğu, kurumların bırakmak istemeyecekleri bir pazarlama iletişimi aracı, sponsor olunanların ise kaybetmek istemeyecekleri bir gelir kaynağı olarak varlığını, gelişimini sürdürmeye ve sponsorluk alanı içindeki payını artırmaya devam edeceği düşünülmektedir.

\section{Kaynakça}

Aktan, M. (2017). Basketbol Sponsorluğunun Marka İmajına Etkisi: Muratbey Uşak Sportif Basketbol Takımı Örneği. Yüksek Lisans Tezi. Marmara Üniversitesi Sağlık Bilimleri Enstitüsü.

Akyıldız, M., Marangoz, M. (2008). Sporda Sponsorluğun Tüketicilerin Satın alma Niyetine Yansiması. Ege akademik bakış, 8(1), 153-166.

Argan, M., Katırc1, H. (2015). Spor Pazarlaması (3.Bask1). Nobel Yayın.

Baş, M. (2008). Spor Sponsorluğu ve Spor Federasyonlarının Sponsorluğa Bakışı Üzerine Bir Araştırma. Gazi Üniversitesi İktisadi ve İdari Bilimler Fakültesi Dergisi, 10 / 3, 111-124. https://doi.org/10.18070/erciyesiibd.437920

Başar, E.E. (2018). Uluslararası Spor Organizasyonlarında Ulusal Markaların Sponsorluk Faaliyetlerinin İncelenmesi: Sponsora Yönelik Tutumun Aracılık Etkisi ve Etkinlikle İlgilenimin Moderatör Rolü. Atatürk Üniversitesi İktisadi ve İdari Bilimler Dergisi, 32 S(1), 157-176. https://doi.org/10.16951/atauniiibd.652901

Bennett, R. (1999). Sports Sponsorship, Spectator Recall, and False Consensus. European Journal of Marketing, 33(3), 291-313. https://doi.org/10.1108/03090569910253071

Brassington, F. Pettitt, S. (2000). Principles of Marketing (Second Edt.). Pearson Education Limited.

Brooks, C. (1994). Sports marketing: Competitive business strategies for sports. Prentice Hall.

Carrillat, F.A. d'Astous, A. (2012). The Sponsorship-Advertising Interface: is Less Better For Sponsors? European Journal of Marketing, 3(4), 562-574 https://doi.org/10.1108/03090561211202611

Collet, P. and Fenton, W. (2011). The Sponsorship Handbook. Jossey Bass Imprint.

Cornwell, T.B., Humphreys, M.S. (2013). Memory For Sponsorship Relationships: A Critical Juncture in Thinking. Psychology and Marketing, 30(5), 394-407. https://doi.org/10.1002/ mar.2061

Cornwell, T. B., Roy, D. P., Steinard, E. A. (2001). Exploring Managers' Perceptions Of The İmpact of Sponsorship on Brand Equity. Journal of Advertising, 30(2), 41-51. https://doi.org/10.1080/00913367.2001.10673636 
Cunningham, S., Cornwell, T.B., Coote, L.V. (2009). Expressing Identity and Shaping Image: The Relationship Between Corporate Mission and Corporate Sponsorship. Journal of Sport Management, 23(1), 65-86. https://doi.org/10.1123/jsm.23.1.65

Çavuşoğlu, S.B., (2011). Türkiye'de Spor Sponsorluğu Çalışmaları Kapsamında Fenerbahçe Galatasaray ve Beşiktaş Spor Kulüplerinin Futbol Takımlarının Ana Sponsorluklarının Bilinirliği Üzerine Bir Araştırma. Doktora Tezi. Marmara Üniversitesi Sosyal Bilimler Enstitüsü.

Danyichuk, K.E. (2000). Tobacco Sponsorship: Spectator Perceptions at an LPGA Event. Sport Marketing Quarterly, 9(2), 103-111.

Dumanlı Kürkçü, D. (2015). Sponsorluğun Marka Değeri Üzerine Etkisi. Yıldız Journal of Art And Design, 2(1), 01-18

Dumont, G. (2016). Understanding Ethnographically Athletes' Perception And Experience of Sponsorship: The Case Of Professional Rock-Climbing. European Sport Management Quarterly, 16(4), 525-542. https://doi.org/10.1080/16184742.2016.1171375

Erdoğan, B.Z., Kitchen, P. J. (1998). Managerial Mindsets And The Symbiotic Relationship Between Sponsorship And Advertising. Marketing Intelligence \& Planning, 16(6), 369-374. https://doi.org/10.1108/02634509810237578

Ferreira, M., Hall, T., Bennett, G. (2008). Exploring Brand Positioning in A Sponsorship Context: A Correspondence Analysis of the Dew Sport Tour. Journal of Sport Management, 22(6), 734761. https://doi.org/10.1123/jsm.22.6.734

Foster, G., O'Reilly, N., Dávila, A. (2016). Sports Business Management: Decision Making Around The Globe. Routledge.

Frederick, H., Patil, S. (2010). The Dynamics of Brand Equity, Co-Branding And Sponsorship in Professional Sports. International Journal of Sport Management and Marketing, 7(1-2), 4457. https://doi.org/10.1504/ijsmm.2010.029711

Glogger, A. (1999). Imagetransfer Im Sponsoring. Frankfurt am Main; Berlin; Bern; New York; Paris; Wien: Lang.

Gordon, C., Cheah, S. (2014). The Meanings of Sports Sponsorship 'Success': Not Just a Transaction but a Relationship. Available at SSRN 2393789.

Gwinner, K.P., Eaton, J. (1999). Building Brand Image Through Event Sponsorship: The Role of Image Transfer. Journal of Advertising, 28(4), 47-57. International Events Group. (2017, January 4). Sponsorship Spending Forecast: Continued Growth Around The World. Sponsorship.com. Retrieved from http://www.sponsorship.com/iegsr/2017/01/04/Sponsorship-Spending-Forecast-ContinuedGrowth-Ar.aspx. https://doi.org/10.1080/00913367.1999.10673595

Hino, Y., Takeda, F. (2019). Market reactions to sport sponsorship announcements: Comparison between sponsors and their rivals. Sport Management Review (Article in press). https://doi.org/10.1016/j.smr.2019.02.002

https://anasponsor.com/sponsorluk-cesitleri-nelerdir/ (Erişim Tarihi: 05.07.2019).

https://blog.anasponsor.com/trabzonspor-qnb-sponsorluk-anlasmasinin-detaylari/ (Erişim Tarihi: 05.07.2019).

http://www.fotospor.com/haber-besiktas-besiktasa-7-yilda-35-milyon-dolar-335177

(Erişim Tarihi:05.07.2019). 
https://www.istekobi.com.tr/kobi-bilgi-merkezi/haberler/thy-euroleague-in-isim-sponsoru-olduh5546.aspx Erişim Tarihi: 05.07.2019)

https://www.pledgesports.org/2017/11/biggest-athlete-sponsorship-deals-in-sport-2/ (Erişim Tarihi: 26.04.2019)

https://rtrsports.co.uk/blog/growth-sponsorship-global-spending/ (Erişim Tarihi:26.04.2019)

https://www.statista.com/statistics/274449/marketing-revenue-of-olympic-games-from-domesticsponsorships/ Erişim Tarhi: 26.04.2019)

https://www.tkf.org.tr/milka-ile-sponsorluk-anlasmasi-imzalandi/ (Erişim Tarihi: 05.07.2019)

http://tr.beinsports.com/fotogaleri/iste-en-pahali-sponsorluk-anlasmalari (Erişim tarihi: 26.04.2019)

https://www.trtspor.com.tr/haber/basketbol/thy-euroleague/2020-yilina-kadar-thy-56178.html

Erişim Tarihi: 05.07.2019)

https://www.sportsjoe.ie/football/man-city-kit-deal-with-puma-194615 (Erişim tarihi: 26.04.2019)

http://www.sponsorship.com/IEG/files/f3/f3cfac41-2983-49be-8df6-3546345e27de.pdf (Erişim Tarihi: 26.04.2019)

https://sponsorship.org/csms-2018-football-super-spenders-report/ (Erişim Tarihi: 26.04.2019)

Jensen, J. A., Cobbs, J. B. (2014). Predicting Return on Investment in Sport Sponsorship: Modeling Brand Exposure, Price, and ROI in Formula One Automotive Competition. Journal of Advertising Research, 54(4), 435-447. https://doi.org/10.2501/jar-54-4-435-447

Jensen, J.A., Wakefield, L., Cobbs, J. B., Turner, B. A. (2016). Forecasting Sponsorship Costs: Marketing Intelligence in The Athletic Apparel Industry. Marketing Intelligence \& Planning. 34(2), 281-298. https://doi.org/10.1108/mip-09-2014-0179

Jobber, D. (2007). Principles and Practice of Marketing (5th ed). England: McGraw-Hill Education.

Kim, Y.K., Ko, Y.J., James, J. (2011). The Impact of Relationship Quality on Attitude Toward a Sponsor. Journal of Business \& Industrial Marketing, 26(8), 566-576. https://doi.org/10.1108/08858621111179840

Lardinoit, T., Quester, P. G. (2001). Attitudinal Effects of Combined Sponsorship And Sponsor's Prominence on Basketball in Europe. Journal of Advertising Research, 41(1), 48-58.

Levin, A.M., Beasley, F., Gamble, T. (2004). Brand Loyalty of NASCAR Fans Towards Sponsors: The impact of fan identification. International Journal of Sports Marketing and Sponsorship, 6(1), 7-17. https://doi.org/10.1108/IJSMS-06-012004-B004

Levin, A.M., Joiner, C., Cameron, G. (2001). The Impact of Sports Sponsorship On Consumers' Brand Attitudes And Recall: The Case of NASCAR Fans. Journal of Current Issues and Research in Advertising, 23(2), 23-31. https://doi.org/10.1080/10641734.2001.10505118

Lock, F. (1988). Kuntsponsoring: Ein Spannungsfelds Zwischen Unternehmen Künstler und Gesellschaft. Dt. Univ. Verl.

Mason, D. S. (1999). What is the Sports Product And Who Buys It? The Marketing of Professional Sports Leagues. European Journal of Marketing, 33(3-4),402-418.

Mason, K. (2005). 'How Corporate Sport Sponsorship Impacts Consumer Behavior', Journal of American Academy of Business, Cambridge, 7(1), 32-35. https://doi.org/10.1108/03090569910253251

Masterman, G. (2007). Sponsorship for a return on invesment. Butterworth-Heinemann (Elsevier). 
Mazodier, M., Rezaee, A. (2013). Are Sponsorship Announcements Good News For The Shareholders? Evidence From International Stock Exchanges. Journal of the Academy of Marketing Science, 41(5), 586-600. https://doi.org/10.1007/s11747-013-0325-x

McDonald, H., Karg, A. (2014). Quantifying the Positive Effects of Sponsor Level, Length, Prominence And Relatedness on Recall And Residual Recall Rates Over Time. Journal of Marketing Communications, 21(5), 372-391. https://doi.org/10.1080/13527266.2013.778323

Meenaghan, T. (1983). Commercial Sponsorship. European Journal of Marketing, 17(7), 5-73.

Morgan, A., Adair, D., Taylor, T., Hermens, A. (2014). Sport Sponsorship Alliances: Relationship Management For Shared Value. Sport, Business and Management: An International Journal, 4(4), 270-283. https://doi.org/10.1108/sbm-12-2013-0044

Okay, A. (2012). Sponsorluk. Der Yayınları.

Özer, A. (2011). Markaya Yönelik Tutumun Sponsorluk Sonrası Marka İmajı ve Satın Alma Eğilimi Üzerindeki Etkisi. Hacettepe Üniversitesi İktisadi ve İdari Bilimler Fakültesi Dergisi, 29(2), 145-174. https://doi.org/10.17065/huiibf.89064

Öztürk, S.A. (2013). Sporda Sponsorluk. (Ed. Metin Argan) Anadolu Üniversitesi Yayınları.

Poon, D.T.Y., Prendergast, G. (2006). A New Framework For Evaluating Sponsorship Opportunities. International Journal of Advertising. 25(4), 471-487. https://doi.org/10.1080/02650487.2006.11072984

Quester, P., Bal, C. (2013). Sport Sponsorship. (In L. Robinson, P. Chelladurai, G. Bodet, \& P. Downward Eds.), Routledge Handbook of Sport Management. Routledge. https://doi.org/10.4324/9780203807224.ch22

Radicchi, E. (2014). Sports Sponsorship Evolution in The Economic Recession: Analytical Evidence From Empirical Cases. Physical culture and sport. Studies and research, 61(1), 51-64.. https://doi.org/10.2478/pcssr-2014-0005

Repucom (2014). European Football Kit Supplier Report 2014. Retrieved from http://repucom.net/reports/european-football-kit-supplier-report-2014

Rifon, N.J., Choi, S.M., Trimble, C.S. Li, H. (2004). "Congruence Effects in Sponsorship: The Mediating Role of Sponsor Credibility and Consumer Attributions of Sponsor Motive", Journal of Advertising, 33(1), 30-42. https://doi.org/10.1080/00913367.2004.10639151

Rowe, W.J., Moore, M. E., Zemanek Jr, J. E. (2019). Three-tiered Sponsorship: A Study of Decision Heuristics Across Multiple Levels of Sport Sponsorship. Innovative Marketing, 9(2), 18-27.

Soyer F. (2003). Sporda Sponsorluk. Gazi Kitabevi.

Schwarz, E.C., Hunter, J.D. (2008). Advanced Theory Practise in Spor Marketing. ButterworthHeinemann.

Şahin, H. M., Koç, S., Yılgın, A. (2003). Beden Eğitimi ve Sporda Sponsorluk. Gaziantepspor Kulübü Spor Eğitim Yayınları. https://doi.org/10.1501/sporm_0000000292

Sports Marketing Dergisi (2007). Nisan 2007 Sayıs1, Y11:1 Say1:1

Tosun, N.B. (2003), Pazarlama Halkla İlişkileri ve Reklam: Bütünleşik Pazarlama iletişsim Yönlü Bir yaklaşım. Türkmen Kitabevi, Beta Basım Yayın A.Ş. https://doi.org/10.14783/maruoneri.678757 
Turner, P., Fuller, P., Karg, A. (2010). Matching the Club to the Sponsor: Perceptions of Australian Football League club sponsorship managers. Journal of Sponsorship, 3(4), 321-332

Walliser, B. (1995). Sponsoring: Bedeutung, Wirkung und Kontrollmöglichkeiten. Springer-Verlag.

Walliser, B. (2003) An International Review of Sponsorship Research: Extension And Update, International Journal of Advertising, 22(1), 5-40. 